\title{
Picture of Norwegian clinical learning laboratories for undergraduate nursing students
}

\author{
Sally J. Wellard ${ }^{\mathrm{a}, *}$, Betty-Ann Solvoll ${ }^{\mathrm{b}}$, Kristin M. Heggen ${ }^{\mathrm{a}, \mathrm{c}}$
}

School of Nursing, University of Ballarat, P.O. Box 663, Ballarat, Victoria 3353, Australia

Department of Health Science, Vestfold College, Norway ${ }^{\mathrm{c}}$ Institute for Nursing and Health Sciences, University of Oslo, Oslo, Norway

Accepted 23 June 2008

\section{KEYWORDS}

Teaching methods; Clinical skills laboratory; Undergraduate; Nursing

Summary Clinical preparation for practice is a vital part of undergraduate education in nursing. This study explored contemporary constructions of clinical skills laboratories in two nursing undergraduate programs in Norway using qualitative collective case study methods. Data were gathered using individual and group interviews and observation during site visits. The data revealed slightly different ways of organizing teaching and experimenting with use of pedagogical methods to facilitate learning of technical skills as well as encouraging students to activate relevant theoretical knowledge. While there was a lively and striking enthusiasm among staff about the way learning was managed within the laboratories, the pedagogical underpinnings for their particular approaches were less certain amongst participants. The paper concludes with the necessity to provide evidence for the outcome of laboratories learning and investigate suitable pedagogical methods for effective teaching and learning of practice skills. Hence, a need for research on transfer of knowledge and skills between the different sites (academy, clinical settings, and laboratories) is identified. c 2008 Elsevier Ltd. All rights reserved.

\section{Introduction}

Nursing, as a practice-based discipline, requires a minimum level of clinical competence for entry to practice (Bjork, 1999; Heath, 2002), therefore, the clinical preparation for practice is a vital part of undergraduate education. While there are numerous opinions about how and where this practical preparation should occur (Neary, 1997; Su et al., 2005; Hilton and Pollard, 2004; Love et al., 1989; Bjork, 1995), there remains little consensus or empirical evidence to guide pedagogical approaches to support students developing nursing knowledge and transferring that knowledge to clinical practice.

The use of practice classrooms, or skills laboratories, has a long tradition in nurse education (Godden and Forsyth, 2000; Scott, 2001; Neary, 1997; Jeffries et al., 2003). Typically, skills laboratories are on-campus spaces that partially reproduce health care settings, most often 'the hospital ward', and are frequently equipped with artefacts of hospitals, including beds, adult and infant mannequins and a range of medical instruments (Cowan and Wiens, 1986; Hilton and Pollard, 2004; Jeffries, 2000; Jeffries et al., 2002). Simulation is the predominant strategy where students are provided with a range of simulated or 'mock' experiences to engage in both directed 
and self-directed learning and performance of clinical nursing activities. Safety is often argued as an important reason for using simulated experiences, because students can develop a level of competency in skills prior to providing direct care for patients. The skills laboratories also provide a safe learning environment for students where they can test and practice their skills without the pressure of 'real' world performance (Freeth and Fry, 2005). Freeth and Fry (2005) reported that students and teachers perceived laboratory learning as valuable, although senior students were less enthusiastic about this learning environment. The use of clinicians in teaching core clinical skills was found to be successful for increasing engagement in laboratory learning in one UK School of Nursing (Hilton and Pollard, 2005). Other innovations in clinical learning include the development of interprofessional training wards within clinical settings, where students from a number of disciplines work together to plan and deliver care (Freeth et al., 2001; Falls-berg and Hammar, 2000). Rystedt (2002) studied the use of simulation for registered nurses becoming nurse specialists in intensive care. He concluded that there are possibilities embedded in simulations, but at the same time there is a crucial need for developing methods for supervision of students. He calls for supervision aimed at integration of simulation with theoretical content and clinical practice.

Student anxiety and employer dissatisfaction with the level of practical competence in new graduates have prompted numerous reports in both nursing and medicine (for example, Santucci, 2004; UKCC, 1999; McManus et al., 1998; Remmen et al., 2001). While there is clearly recognition of issues associated with skill acquisition there is limited research about what might constitute a solution. To date the major emphasis in the nursing literature has been on assessment, simulation and single case reports of innovative teaching strategies.

There is an inherent assumption in this literature that clinical laboratories are necessary, but there has been limited discussion of what constitutes the necessary infrastructure for undergraduate nursing clinical laboratories, nor how they vary across different countries. Interestingly Scott (2001) presented a range of criteria for practical success of clinical learning laboratories in the UK but offered only anecdotal experience for these recommendations. Childs (2002) undertook a national survey investigating the physical structure, resources, budget and administration of clinical laboratories in nursing schools in the USA, finding a range of supports used to assist directed and self-directed student learning. Barriers to successful use of laboratories included mismatches between curriculum and resources, and issues associated with available and appropriate staff, space, equipment and technology.

Given the paucity of knowledge about what pedagogical approaches and infrastructure can facilitate learning in clinical skills laboratories, we undertook to explore the current construction of clinical skills laboratories in nursing undergraduate programs in Norway. This built on our previous exploration of skills laboratories in Australia (Wellard et al., 2007). This paper presents the findings of this research by describing the ways faculty report their use of laboratories. Additionally a number of challenges are identified about the role of laboratory learning in the overall preparation of undergraduate nursing students. The following section provides background to the contemporary context of pre-registration nurse preparation in Norway.

Nurse preparation in Norway 
Nurses in Norway are now prepared to Bachelors level over 3 years in regional university colleges (Lorensen et al., 1998). Nursing curricula are based on national regulations with some variations at the institutional level in the delivery of programs. All programs include both theoretical and clinical learning components. The current national regulations require students to undertake 60 weeks (90 credits which is equivalent to $2250 \mathrm{~h}$ ) of clinical studies in the BN program. These clinical studies require students to spend 50 weeks $(1875 \mathrm{~h})$ involved in direct contact with patients and their relatives and the remaining 10 weeks ( 375 h) is for "training and reflection upon practical skills", mostly worked on in skills laboratory (Kunnskapsdepartementet, 2008). Schools of Nursing operate within the Norwegian higher education system that has experienced significant change over the past two decades, where all disciplines are charged with curriculum renewal that will enhance student learning. These changes are supported within a legislative framework requiring all teaching and learning in higher education to be based on scientific knowledge and the best known practice. The Norwegian Agency for Quality Assurance in Education (NOKUT) was established in 2003 to assess and certify the quality of higher education (www.nokut.no). NOKUT undertook a review of all Schools of Nursing in Norway (31 in total) in 2004. The outcomes of this review were very disappointing, with the majority of Schools assessed as not meeting the criteria for competency. Fourteen institutions were instructed to develop and document the scientific basis for the teaching and learning within their programs with measurable improvements expected.

One recent initiative that is arguably supporting improved evidence base to nurse education has been the development of a national resource for practical nursing procedures. The PPS (Practical Procedures in Nursing) is a commercially published online database of documented and quality assured skills (www.akribe.no) in nursing that was adopted for use in Norwegian Schools of Nursing in 2006. The database entails approximately 300 fundamental skills in nursing, elaborated in accordance with national standards and recent research evidence and was developed in consultation with a wide range of experts in the health field (including nurses, physicians, physiotherapists) from both clinical and academic backgrounds. The electronic self-directed learning program is mainly text-based with links to static illustrations, video sequences to demonstrate procedures and lists of reference materials from the literature. Additionally, the PPS offers a self-test facility with feedback, and a training program for medication dose calculations.

\section{Methods}

This study aimed to explore contemporary constructions of clinical skills laboratories in nursing undergraduate pre-registration programs in Norway. Specific objectives included identifying the scope and foci of nursing clinical learning laboratories in Norway; describing the pedagogy used in the laboratory components of the Norwegian BN programs; and the exploration of relationships between the clinical learning laboratories and theoretical content of the courses. Collective case study design (Stake, 1995; Bennett and Elman, 2006; Payne et al., 2007) was adopted and data were collected using qualitative methods. Case studies have been extensively used in education, psychology, as well as business administration (Banister, 2008). The case study reported here is a descriptive study where we are drawing a picture of what types of teaching and learning activities are enacted in laboratories and how do teachers reflect and argue on the use and effectiveness of laboratory learning in the Norwegian context.

Following approval from the appropriate human research ethics committee, two Schools of Nursing that are acknowledged for their specific interest in clinical skills laboratory learning were contacted and invited to participate in the study. Individual staff members were provided with information and 
asked to give consent prior to the commencement of data collection.

Data were initially captured in email exchange between the Australian and Norwegian investigators where descriptions of the role of laboratories within curricula, the approaches to teaching and assessment, and the perceived barriers to optimal clinical laboratory learning were captured. This provided an opportunity for shared reflection prior to site visits by all investigators (one from Australia, the other two from Norway). Data were gathered at the two sites with a combination of touring the facilities, observation of teaching sessions and interviews with interested teaching staff. A total of 13 participants joined the study, 8 participants from one school and 5 from the second school. All three investigators participated in the data collection, asking follow up questions or validating statements like "what I understand you are saying is...". The discussions were lively lasting between 2 and $3 \mathrm{~h}$. Three questions were used to focus discussions: what is good about the laboratories, what is not working, and how do you know what you are doing is good? Data were recorded in hand notes and audio-taped with permission of the participants. English was the main language spoken during the field work, however where participants found it difficult to express their ideas in English, they conferred in Norwegian with the Norwegian investigators assisting them in finding English expression for their ideas. The investigators also discussed amongst themselves during the site visits which assisted in building a common understanding of the data as well as focusing questions that inspired both the investigators and participants to deeper reflection on laboratory learning.

Analysis of data was thematic and involved each of the investigators identifying their own schema of themes through reading field notes and listening to the audio tapes (Kvale, 2007). Subsequently, findings were shared and similarities and differences in analyses noted. Areas of disagreement required a re-examination of the data as a team and further discussion until agreement on analysis was reached.

\section{Findings}

The two Schools of Nursing in this study approached developing student knowledge and skills for practice in different ways. Initially we provide an overview of each of the schools, describing the individual approaches and challenges participants identified. Subsequently common themes that were evident across the two sites are presented: the vital importance of laboratories; pedagogy and integration in learning; student motivation to learn, and who can teach in laboratories.

School 1

School 1 is located in a medium sized university college with approximately 3000 full time students enrolled in a range of disciplines at Bachelor and Master level awards. The School of Nursing enrolls students twice a year in the Bachelor of Nursing, with a total intake of 140 students each year. The clinical laboratory was built in 1999 and is a close facsimile of a contemporary Norwegian hospital ward. The laboratory is composed of 6 patient care rooms with 4 beds in each, and additional rooms for: medication room; decontamination and cleaning room; clean procedures room; a nurses' office; storage room for large items; and, modular storage systems for linen and disposable equipment.

Following a recent curriculum review, a problem based learning approach was adopted, with students now undertaking two units of study in clinical skills during their course. These are undertaken in the first and third semesters of the Bachelor of Nursing. Each unit of study comprises of $4 \mathrm{~h}$ 
contact for students in the laboratory per week for 10 weeks with a student to teacher ratio of 9-11:1 and students are required to pass a clinical skills test before progressing to the next level in the course. The first unit develops foundational nursing skills (for example: vital signs, hygiene care) and the second develops students' skills in critical, acute and chronic care (for example: intravenous fluid treatment, enteral feeding). Case studies, together with teacher demonstration of skills, are used to initiate learning; students subsequently practice the skills and at the completion of each week demonstrate their skills to teacher and peers. The teaching approach in the course assumes students will take a level of responsibility for their learning, and the School has adopted the Praktiske Prosedyrer Sykepleietjenesten (practical procedures in nursing) [PPS] as a requirement for students to use to support their skill development.

\section{School 2}

School 2 is also located in a medium sized University College that offers Bachelor and Master programs with an over all student body of 1700 students across 5 disciplines including nursing. The School of Nursing enrolls 150 students annually in the Bachelor of Nursing course.

The laboratory is also relatively new and was designed to accommodate the combination of more traditional clinical skills teaching with high fidelity simulation based learning using a Laerdal Sim-Man ${ }^{\text {TM }}$. The laboratory occupies a large space with built rooms in a central core area and a large $U$ shaped perimeter space where 22 beds are distributed. The $U$ shaped perimeter serves as the 'practice' space for students, with a number of flat screen monitors with access to internet and video replay distributed within the space to support independent and group learning. Students are able to access the PPS resource while in the laboratory to check aspects of procedures. Each bed had privacy screens and other fittings similar to contemporary hospital settings. The central space housed service areas (clean room, decontamination space, medication storage etc.), a small lecture theatre with facilities for live video feed of the 'practice' area, and office space for managing simulation scenarios.

The curriculum in this School incorporates clinical skills laboratories in each of the six semesters of the course and closely aligns laboratory experiences with off-campus clinical learning. Students are required to attend intermittently scheduled clinical skills laboratory classes during their off-campus experience for reflection and skill extension. The adopted approach to teaching in this school is structured in a linear hierarchical way with students expected to engage in pre learning that is assessed prior to classes in the laboratory, followed by instruction using demonstration and return demonstration, and selected high fidelity simulation experiences. The simulation sessions with small groups (2-3 students) can be viewed 'live' by their peers in the lecture theatre and subsequently replayed for all participants to discuss and reflect on aspects of the 'care' delivered.

Vital importance of laboratories

The first theme common to both schools related to staff perceptions of laboratories as vital in the development of student learning for practice. Creation of environments that mimic the practice setting was relayed as important by staff at both sites, and they were clearly proud of their achievements. Considerable effort had been made to produce spaces that closely resembled contemporary practice, and participants emphasised this repeatedly as they demonstrated the various facets of their facility. The laboratories in both settings reinforce the hospital as the nursing 
practice environment, and students are expected to dress in the laboratory as they would if in a hospital setting. Staff in both schools demonstrated a keen interest in participating in this research and there was clearly a high level of engagement and commitment to developing quality laboratory experiences for students.

There was enthusiastic discussion about their approach and commitment to 'getting it right'. Participants described the clinical skills laboratory as a classroom that provides students with opportunities to develop skills and confidence at their own pace, without the complexity that patients in clinical settings bring to a situation. Students can alternate between physically attempting a skill and reference to expertise, either in books, the PPS online resource, or staff who are available to support their learning. Small group size was attributed to helping form close working relationships where teachers are able to gain understanding of individual student learning styles and difficulties, therefore offering more targeted remediation.

\section{Pedagogy and integration in learning}

The second theme identified in the data related to pedagogy and integration of learning across the theoretical, laboratory and clinical learning settings. While there was lively discussion about the way learning was managed within the laboratories, the pedagogical underpinning for their particular approach was less certain amongst participants. Faculty asserted that students learn in the laboratory because it is permissible to make mistakes and confidence develops through repetitive practice until a skill is mastered. The faculty at both sites argued that their laboratory learning programs aimed to develop students to become proactive practitioners and incorporated a number of strategies to assist in this goal. First, students are encouraged to problematize theory-practice connections by challenging them to provide rationales for their actions. Second, activities using simulation (either high fidelity, or role play and practice on peers) engage students to explore their emotional and ethical development with critical reflective contributions from their peers and teachers about their performance. Finally, the laboratory structure facilitates active control and limiting of clinical scenarios to facilitate specific learning at any one time. As one participant summarized "situations can be 'frozen', action can be stop/ started, and rewound and analyzed".

Participants at both sites identified difficulties associated with integrating theoretical knowledge with the teaching and learning activities in the laboratories. Laboratory sessions were acknowledged as having a focus on procedures and students as well as teachers were caught in the laboratory context which "forced" them to concentrate on the 'how' of doing clinical practice at the cost of 'why' it is done. This was identified as another challenge; how to integrate teaching of caring attitudes into laboratory teaching when the predominant focus of the laboratory is on technical skill acquisition. For example, teachers related difficulty associated with the 'unreal' caring relationship students form with mannequins or fellow students acting as patients. Different teaching approaches had been adopted in an attempt to increase the integration of a variety of knowledge components. Case based methods were frequently used, with either a single scenario used or an unfolding case history over several sessions. 
The third theme related to the perceived motivation of students to engage in laboratory learning. Participants from both sites reported variability in student preparation and engagement in the laboratory learning program as a major challenge. Student motivation for learning basic skills associated with personal care was low, but as they progressed to more technologically challenging tasks their motivation increased. Participants also reported students were less motivated to undertake the reading about the procedure; they wanted to practice on either each other or on a mannequin. This eagerness to practice was seen among teachers as positive but it was at the same time a problem to motivate students to engage in deeper learning of the knowledge embedded in the skills.

Staff at School B reported introducing a pre-laboratory test because they had found students did not prepare adequately for laboratories. Laboratories were available for students to access outside of formal class time, but as staff from School A reported, there was limited uptake of this opportunity by students, except when a test was imminent.

\section{Who can teach in laboratories?}

The last theme explores the desirable characteristics of teaching staff in laboratories. Laboratories were in part described by participants as an arena between the academy and clinic and this prompted a discussion about the desired qualifications and competence preferred for teachers in the skills laboratory. No overall agreement was evident across all participants but there was general acknowledgement that a range of competencies were needed to support student learning. On one hand recency of practice was suggested as bringing students the most contemporary approaches and routine practices from clinical environments. School 2 has adopted the strategy of including a clinical nurse from the local hospital in some laboratory sessions to facilitate increased integration between the academy and the clinic in laboratory teaching. On the other hand, many participants argued that recent practice was less essential because all teachers in the laboratories were nurses and as one participant expressed: "the principles underpinning practice are familiar to any nurse regardless of their generation".

\section{Discussion}

Laboratory learning was viewed by participants in this study as essential in undergraduate nurse education and has similarly been reported by other studies (Love et al., 1989; Neary, 1997; Hilton and Pollard, 2004; Freeth and Fry, 2005; Su et al., 2005; Wellard et al., 2007). The belief that laboratories offer students a chance to 'practice' outside the complexity of 'real' practice settings, in a safe space has also been argued in the literature as a rationale for increasing the volume and fidelity of simulation in nursing education (for example, Jeffries, 2005). Indeed, in the UK the Nursing and Midwifery Council recently agreed that up to $300 \mathrm{~h}$ of practice learning can be assess in simulated learning environments (NMC, 2007). However, participants in this study, as in previous work have little empirical evidence to support this belief. It is debateable that the safe practicing of basic skills in laboratories makes future nurses better prepared for coping with reality. Researchers (Benner, 1984; Benner et al., 1996; Sullivan, 2005) have emphasised the complexity of knowledge and skills embedded in nurses' problem solving and underlined the importance of facing uncertainty when planning their work to meet the needs of a variety of individual clients and situations.

The findings from our study reveal staff had few concerns about the possible risks and limitations 
with the use of laboratories. Staff at both schools shared an enthusiastic belief in the possibilities of using laboratories, and had over the preceding years experimented with a number of different teaching strategies and structures for delivering clinical skill learning. Staff enthusiasm was also visible in their willingness to explore and discuss different ways of addressing the imperative from the NOKUT assessment for research based teaching in laboratory classes. Several options were mentioned but participant uncertainty about what might be best practice was striking. Neither of the schools visited could provide evidence of evaluation of their assumption that laboratories are a key factor in developing new nurses for practice, or evaluation of the success of various approaches adopted. As identified in the Australian study (Wellard et al., 2007), there is considerable rhetoric in nursing education about the value of laboratories but little data to confirm that the high investment in laboratories - both capital for developing sophisticated spaces, and staffing with reduced staff student ratios - is warranted.

This study was timely with Norwegian Schools of Nursing challenged to demonstrate an increase in quality. The PPS has been a welcomed initiative, providing students and staff with access to a learning resource with high accessibility and based on best available evidence. Development of similar resources in other countries may provide a useful adjunct to other teaching strategies to assist student learning.

Issues related to variability in student motivation to be prepared for and engaged in aspects of laboratory learning was of concern to participants in this study and has been noted in undergraduate students in other disciplines, including physiotherapy (Ward and Gracey, 2006) and medicine (Weyrich et al., 2008). Arguably a range of factors influence student motivation to prepare for classes, as Norman and colleagues (2005) found students need to balance competing demands between study and other aspects of their lives as well as managing a perceived high study load. This is a growing challenge for nursing students as curricula becomes increasingly overcrowded (Dalley et al., 2008). Additionally, Johnson and Romanello's (2005) discussion of the generational diversity in student cohorts is helpful in understanding the different learning characteristics and needs which possibly account for variability in motivation to engage in different laboratory activities. Exploration of greater learner-centered approaches to laboratory learning may assist in increasing student engagement (Dalley et al., 2008).

There was a desire from all participants in the laboratories to engage nurses with current clinical experience in the instruction of students in laboratories because they were seen as knowing what currently counts as valid practice. There is little evidence available to support this assumption. What is known from Rystedt's (2002) study on simulation in health care professions is the necessity for developing methods for supervision that facilitate integration of clinical and theoretical knowledge in students experiences in laboratories. A possible consequence of Rystedt's study is that it may be less important where teachers are from (the academy or clinic), but more importantly is the methods used for teaching and supervision.

NOKUT has forced Norwegian nurse educators to strengthen their use of evidence for teaching nursing. There in lies a paradox that the teaching methods used to pass on the evidence based knowledge to the next generations of nurses are lacking in evidence of their effectiveness. There are clearly many areas in need of investigation related to laboratory learning. A few are mentioned here: what sort of simulation promotes integration of knowledge rather than separation of the intellectual, physical and ethical aspects of knowledge for practice; does laboratory learning support transfer of knowledge by students from the classroom to the clinical setting; how do we 
address the challenge from industry to increase work readiness?

Conclusion

This study has drawn a broad picture of how teaching and learning in laboratories is organized and practiced in two different nursing schools in Norway. In spite of differences, mainly the use of high fidelity simulation in one of the sites, staff at both schools shared a similar enthusiasm and belief in the possibilities laboratories offer nursing students trying to master basic nursing skills and reflect on their own practice. There is at the same time a striking lack of research based evidence demonstrating the outcome of laboratory learning. There are significant questions that need to be answered, including: What are the benefits and limits of teaching and learning in laboratories compared to 'real' world training? Are there different pedagogical methods suitable for different settings? Based on impressions from our study there is a great need to explore the transfer of knowledge and skills between different arenas - academy, different clinical environments, and laboratories.

\section{References}

Banister, P., 2008. Forensic psychology. In: Willig, C., Stainton-Rogers, W. (Eds.), The Sage Handbook of Qualitative Research in Psychology. Sage, Thousand Oakes, CA, pp. 505-523.

Benner, P., 1984. From novice to expert. Excellence and Power in Clinical Nursing Practice. Addison-Wesley Publishing Company, CA.

Benner, P., Tanner, C.A., Chesla, C.A., 1996. Expertise in nursing practice. Caring, Clinical Judgment and Ethics. Springer Publishing Company, NY.

Bennett, A., Elman, C., 2006. Qualitative research: recent developments in case study methods. Annual Review of Political Science 9, 455-476.

Bjork, I.T., 1995. Neglected conflicts in the discipline of nursing: perceptions of the importance and value of practical skill. Journal of Advanced Nursing 22 (1), 6-12.

Bjork, I.T., 1999. Hands-on nursing: new graduates' practical skill development in the clinical setting. Ph.D. Dissertation. University of Oslo, Norway.

Childs, J., 2002. In: Clinical resource centers in nursing programs. Nurse Educator 27 (5), 232-235.

Cowan, D., Wiens, V., 1986. Mock hospital: a preclinical laboratory experience. Nurse Educator 11 (5), 30-32.

Dalley, K., Candela, L., Benzel-Lindley, J., 2008. In: Learning to let go: the challenge of de-crowding the curriculum. Nurse Education Today 28, 62-69.

Fallsberg, M.B., Hammar, M., 2000. Strategies and focus at an integrated, interprofessional training ward. Journal of Inter-professional Care 14 (4), 337-350.

Freeth, D., Fry, H., 2005. Nursing students' and tutors' perception of learning and teaching in a clinical skills centre. Nurse Education Today 25, 272-282.

Freeth, D., Reeves, S., Goreham, C., Parker, P., Haynes, S., Pearson, S., 2001. 'Real life' clinical learning on an inter-professional training ward. Nurse Education Today 21, 366- 372.

Godden, J., Forsyth, S., 2000. Defining relationships and limiting power: two leaders of Australian nursing, 1868-1904. Nursing Inquiry 7, 10-19.

Heath, P., 2002. National review of nursing education 2002: our duty of care. Australian Government Report for the Department of Education, Science and Training and the Department of Health and Ageing, Canberra.

Hilton, P., Pollard, C., 2004. Supporting clinical skills developments. Nursing standard 18 (35), 31-36. 
Hilton, P., Pollard, C., 2005. In: Enhancing the effectiveness of teaching and learning of core clinical skills. Nurse education in practice 5, 289-295.

Jeffries, P.R., 2000. Technology trends in nursing education: Next steps. Journal of Nursing Education 44 (1), 3-4.

Jeffries, P., Rew, S., Cramer, J., 2002. Student-centred versus traditional methods of teaching basic nursing skills in a learning laboratory. Nursing Education Perspectives 23 (1), 14-19.

Jeffries, P.R., Woolf, S., Linde, B., 2003. Technology-based vs. traditional instruction: A comparison of two methods for teaching the skill of performing a 12-led ECG. Nurse Education Perspectives 24 (2), 70-75.

Jeffries, P.R., 2005. A framework for design, implementing, and evaluating simulations used teaching strategies in nursing. Nurse Education Perspectives 26 (2), 96-104.

Johnson, S.A., Romanello, M.L., 2005. Generational diversity: teaching and learning approaches. Nurse Educator 30 (5), 212-216.

Kunnskapsdepartementet, 2008. Rammeplan for sykepleierutdanning. Kunnskapsdepartementet, Oslo.

Kvale, S., 2007. Doing interviews. Sage, London.

Lorensen, M., Jones, D.E., Hamilton, G.A., 1998. Advanced practice nursing in Nordic countries. Journal of Clinical Nursing 7, 257-264.

Love, B., McAdams, C., Patton, D., Rankin, E., Roberts, J., 1989. Teaching psychomotor skills in nursing: a randomized control trial. Journal of Advanced Nursing 14, 970-975.

McManus, I.C., Richards, P., Winder, B.C., 1998. Clinical experience of UK medical students. Lancet 351 (9105), 802-803.

Nursing and Midwifery Council (NMC), 2007. Supporting direct care through simulated practice learning in the preregistration nursing programme. NMC Circular 36/2007, <www.nmc_uk.org> (accessed 23.05.2008.).

Neary, M., 1997. Project 2000 students' survival kit: a return to the practical room (nursing skills laboratory). Nurse Education Today. 17, 46-52.

Norman, L., Buerhaus, P.I., Donelan, K., McCloskey, B., Dittus, R., 2005. Nursing students assess nursing education. Journal of Professional Nursing 21 (3), 150-158.

Payne, S., Field, D., Rolls, L., Hawker, S., Kerr, C., 2007. Case study research methods in end-of-life care: reflections on three studies. Journal of Advanced Nursing 58 (3), 236-245.

Remmen, R., Scherpbier, A., van der Vleuten, C., Denekens, J., Derese, A., Hermann, I., Hoogenboom, R., Kramer, A., Van Rossum, H., Van Royen, P., Bossaert, L., 2001. Effectiveness of basic clinical skills training programmes: a cross-sectional comparison of four medical schools. Medical Education 35 (2), 121-128.

Rystedt, H., 2002. Bridging practices. Simulation in education of health-care professions. Ph.D. Dissertation. University of Gothenburg, Sweden.

Santucci, J., 2004. Facilitating the transition into nursing practice: concepts and strategies for mentoring new graduates. J Nurses Staff Dev. 20 (6), 274-284.

Scott, C., 2001. Back to basics. Nursing Management 8 (5), 16- 19.

Su, W.M., Osisek, P.J., Starnes, B., 2005. Using the revised Bloom's taxonomy in the clinical laboratory. Nurse Educator 30 (3), 117-122.

Sullivan, W.M., 2005. Work and Integrity. The Crises and Promise of Professionalism in America, second ed. Jossey-Bass, USA.

Stake, R.E., 1995. The Art of Case Study Research. Sage, Thousand Oaks.

UKCC, 1999. Fitness for practice. The UKCC Commission for Nursing and Midwifery Education. Chair: Sir L. Peach, United Kingdom Central Council for Nursing, Midwifery and Health Visiting, 
London.

Ward, A., Gracey, J., 2006. Reflective practice in physiotherapy curricula: a survey of UK university based professional practice coordinators. Medical Teacher 28 (1), e32-e39.

Wellard, S.J., Woolf, R., Gleeson, L., 2007. Exploring the use of clinical laboratories in undergraduate nursing programs in regional Australia. International Journal of Nursing Education Scholarship 4(1) article 4, <http://www.bepress.com/ijnes/ vol4/iss1/art4> (accessed 10.02.2007.).

Weyrich, P., Schrauth, M., Kraus, B., Habermehl, D., Netzhammer, N., Zipel, S., Jünger, J., Riessen, R., Nikendei, C., 2008. Undergraduate technical skills training guided by student tutors - Analysis of tutors' attitudes, tutees' acceptance and learning progress in an innovative teaching model. BMC Medical Education 8, 18. 